\title{
Soft-tissue rim sign
}

\section{Lauren Gates, Andres Ayoob, David DiSantis}

Department of Radiology, University of Kentucky, 800 Rose Street, Lexington, KY 40536-0293, USA

A useful clue during CT evaluation of urinary tract calculi, the soft-tissue rim sign represents ureteral wall edema surrounding a calculus at the level of stone impaction. Circumferential soft tissue surrounds the high attenuation value calculus (Fig. 1) [1, 2].

This rim sign can be helpful in distinguishing ureteral calculi from venous calcifications (phleboliths) that typically lack a circumferential soft-tissue margin, but instead have a "tail" of soft-tissue attenuation thought to represent the thrombosed parent vein - one of the several "comet-tail" signs (Fig. 2) [3]. These clues are particularly helpful in patients with a paucity of intra-abdominal fat, in whom the ureter is difficult to identify.

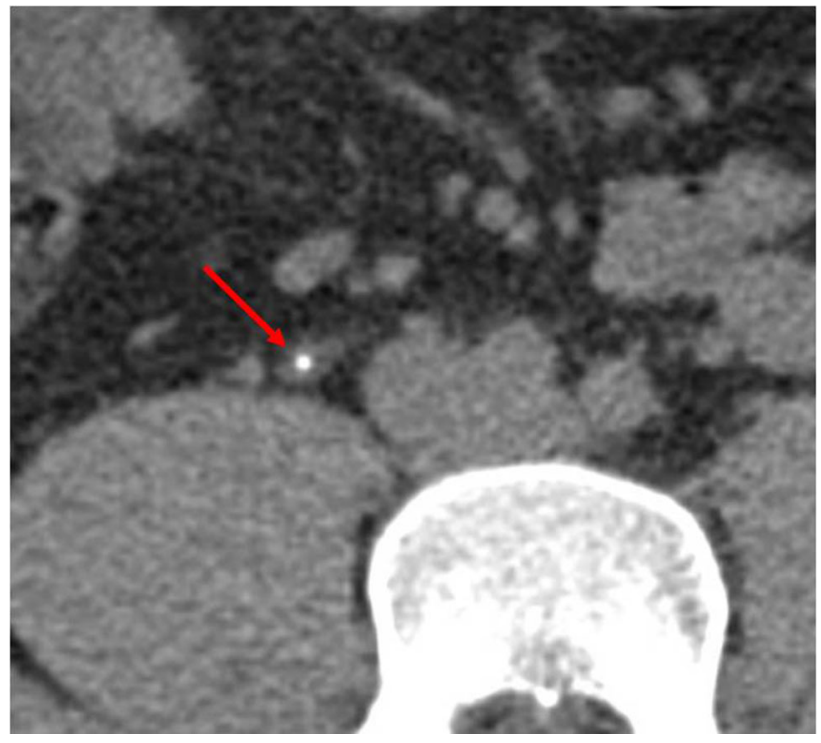

Fig. 1. Axial non-contrast CT at the level of the mid-right ureter. Note the circumferential soft-tissue rim (red arrow) surrounding the high attenuation ureteral calculus.

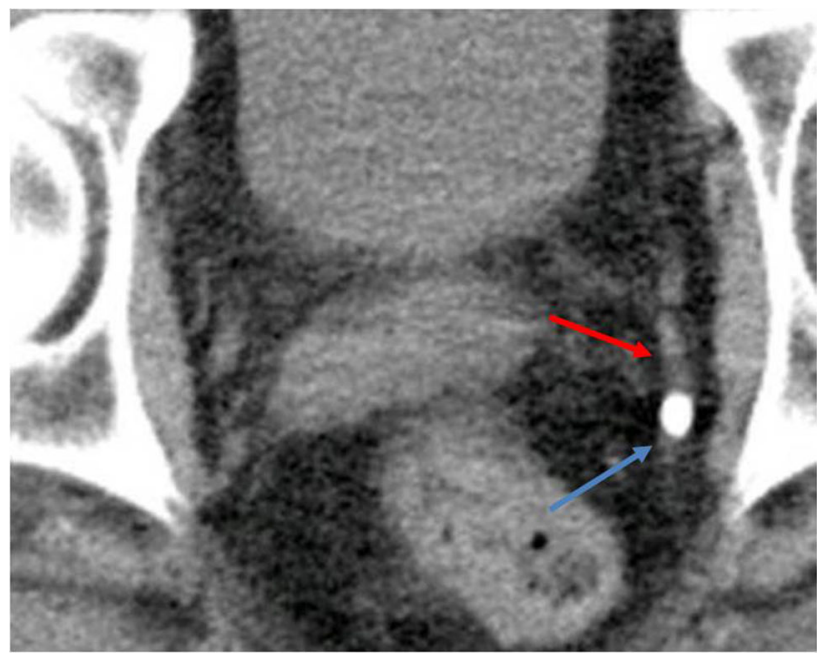

Fig. 2. Axial non-contrast CT at the level of the left distal ureter. The left pelvic phlebolith (blue arrow) lacks the circumferential soft-tissue rim typical of a ureteral calculus. Note the "tail" of soft tissue extending to the calcification (comettail sign, red arrow).

Unfortunately, the rim sign can be absent with ureteral calculi larger than $4 \mathrm{~mm}$ or when the calculus lodges at the ureterovesicle junction [1].

\section{References}

1. Guest AR, Cohan RH, Korobkin M, et al. (2001) Assessment of the clinical utility of the rim and comet-tail signs in differentiating ureteral stones from phleboliths. Am J Roentgenol 177(6):1285-1291

2. Dyer RB, Chen MY, Zagoria RJ (2004) Classic signs in uroradiology. Radiographics 24(Suppl 1):S247-S280

3. Boridy IC, Nikolaidis P, Kawashima A, et al. (1999) Ureterolithiasis: value of the tail sign in differentiating phleboliths from ureteral calculi at nonenhanced helical CT. Radiology 211(3):619-621 